\title{
EL POEMA DE AMOR QUE PROMETIÓ EL DANTE
}

En memoria de mi profesor Joaquín Barceló

Arturo Fontaine*

\begin{abstract}
$\overline{R A}$ Abordo la lectura directa de La Divina Comedia como obra literaria, pensando en un lector contemporáneo, y dejando en un segundo plano su dimensión alegórica teológico-cristiana. No busco negar ese sentido alegórico -obviamente está ahí-. Más bien, quiero centrar la atención en lo que aparece en el poema mismo, y a partir de lo cual se pueden o no elaborar dichas interpretaciones de segundo grado. Dante afirmó que "la forma o el modo" de tratar la materia es "poético, ficticio, descriptivo, abierto a la digresión, metafórico..." (Carta al Can Grande) Desde este ángulo recorro y comento algunas escenas del poema y la condición existencial en el Infierno, el Purgatorio y el Paraíso.
\end{abstract}

Dante es un reportero que recorre el Infierno con una cámara entrevistando a los prisioneros. Su guía, como todo el mundo sabe, es Virgilio. Quiere que los condenados le cuenten por qué están ahí. Ellos notan que se trata de un visitante: "este parece vivo por el movimiento de la garganta" (Inf. XXIII, 88). Él les ofrece que su relato se conozca en la tierra. Los prisioneros quieren ser recordados por los vivos: "cuando estés en el dulce mundo, te ruego me recuerdes a los demás..." "Si vuelves a contemplar las hermosas estrellas, cuando quieras decir "ahí estuve", haz que la gente "se acuerde de nosotros"”' (Inf. VI, 88-89 y XVI, 82-85).

Dante también les trae noticias. Pues "si alguien no nos da noticia, nada sabemos de las cosas humanas" (Inf. X, 104-105). Los condenados, desde ese lugar "que se traga todo el mal del universo", están, entonces ávidos por saber qué ha pasado en el mundo que abandonaron (Inf. VII, 18).

“¿Dónde está mi hijo? ¿Por qué no está contigo?”, le pregunta el padre del poeta Guido Calvacanti al no verlo con él, siendo tan amigos. Y al contestarle, el padre grita: “Cómo dijiste fue? ¿No vive ya?” Y al notar que Dante se tarda en responderle, se hundió de espaldas “y no volvió a aparecer” (Inf. X, 60 y 67-73).

Profesor del Departamento de Filosofía de la Universidad de Chile y de la Facultad de Artes Liberales de la UAI. Sus últimos libros son La vida doble (Tusquets) y La pregunta por el régimen político (Fondo de Cultura Económica). 
Casi todos son personajes reales, muchos, como el padre de Guido, del tiempo del Dante. Sus historias son breves y rápidas. Comienzan, por ejemplo, así:

“Hace poco que caí desde Toscana en este feroz abismo. Llevé un vida más bestial que humana... Soy Vanni Fucci, el bestia... Más me duele que me hayas hallado en la miseria en que me ves, que el haber sido arrebatado de la otra vida"... Y continúa su relato Vanni Fucci (Inf XXIV, 123-125 y 133-135).

Intento una lectura directa de la La Divina Comedia como obra literaria. Tengo en mente al lector contemporáneo. Dejo en un segundo plano su sentido alegórico teológico-cristiano que ha ocupado tanto a los especialistas en Dante ${ }^{1}$. No pretendo negarlo. Por cierto, está ahí. Pero quiero centrar la atención, principalmente, en lo que se muestra en el poema mismo y a partir de lo cual, se pueden o no proponer interpretaciones alegóricas o de segundo grado. El propio Dante sugiere que hay que mirar "la doctrina que se esconde bajo el velo de los versos extraños" (Inf, IX, 61-63). Sin embargo, plantea que "debe ir siempre delante el sentido literal, por estar incluidos en este todos los demás" (El Convite, II, I 8-10). Y en una carta cuya autenticidad hoy algunos ponen en duda - pero que probablemente refleja su pensamiento- afirma que "el sentido de esta obra no es único sino que plural" y "la forma o el modo" de tratar la materia es "poético, ficticio, descriptivo, abierto a la digresión, metafórico..." (Carta al Can Grande). Es desde este ángulo que recorro y comento algunas escenas y considero la naturaleza existencial del Infierno, el Purgatorio y el Paraíso.

El lenguaje es sencillo, exacto, natural. Elliot habla de su "estilo muy escueto y austero", donde la "más ligera vaguedad o imprecisión es inmediatamente percibida" (p. 171). Los tercetos endecasílabos se suceden de tal modo que el primer verso rima con el tercero, y el segundo rima con el primer verso del terceto siguiente, y así sucesivamente. El esquema de la "terza rima" es abc bcb cdc ded... Por tanto, cada terceto tiene 33 sílabas. Beatriz estará presente en 33 cantos del poema. Hay muchas simetrías numéricas así. Iremos encontrando en el Infierno y el Purgatorio a quienes fueron dominadas sin tasa ni medida por sus impulsos -la lujuria, la gula, la ira, la pereza- y conoceremos avaros, dilapidadores, codiciosos, soberbios, envidiosos, ladrones, suicidas, asesinos, tiranos, usureros, aduladores, hipócritas, sembradores de discordias, falsarios, traidores... El poema es una vertiginosa sucesión de historias de vida intensas y dramáticas.

Hubo una acción, una conducta que definió el destino del que habla para siempre. Así es el Infierno. "Ya nada pasa para ellos o, más bien, lo que les pasa seguirá pasando para siempre" (Auerbach 1929). Los personajes son individuos delienados con poquísimas pinceladas y el efecto es de una asombrosa precisión. Dante capta la impresión de la persona viva. Los personajes han "producido su circunstancia para sí", dice Hegel, "para su individualidad y son eternos no en nuestra representación sino en sí mismos" (Hegel 1842, p. 794). Cada castigo infernal es la contracara, la repetición del reverso

Ver sobre el tema, entre tantos ejemplos, Erich Auerbach 1929, Charles S. Singleton 1954, John Freccero 1993, James C. Kriesel 2019. 
autodestructivo de ese acto que fijó su porvenir. Los que no se arrepienten, se quedan pegados al mismo mal. "La agonía" en el Infierno no se debe "tanto a la aflicción sino a la auto-aflicción... a la auto-confrontación” (Took 2020, p. 149 y p. 160).

El Dante quiere conocer estas historias que va a escribir en su "comedia". Lo de "divina" lo agregará, más tarde, un editor haciéndose eco de la celebración de Boccacio. Los diálogos son concisos y absorbentes. Se acerca a los prisioneros con una mezcla de curiosidad y compasión. En alguna ocasión, su curiosidad es intrusa y raya en lo malsano. Se lo reprocha Virgilio: "el deseo de oír tales cosas es muy bajo deseo" (Inf. XXX, 148). Pero prima su compasión. Dante está reflexionando y continuará haciéndolo: “¿puede haber justicia sin misericordia, sin compasión?” (Mazzotta 2014, p. 40). "Quería detenerme a llorar..." Los lamentos de la última fosa "hieren como flechas con puntas de piedad". Con las manos se cubre los oídos (Inf. XXIX, 1-3 y 43-45). A menudo, se demora. Virgilio lo apura. No hay tiempo. El viaje sigue. La Comedia es uno de los grandes poemas "más fragmentados y, al mismo tiempo, más unificados de la tradición occidental" (Pertile 2019, p. 25). Por eso el magnetismo que ejerció en Elliot y en Pound, como se puede comprobar en The Waste Land y The Cantos. También en Virginia Woolf. "La clase de deuda que tengo con Dante es de las que van acumulándose, no de las que se limitan a un solo período de la vida" (Elliot, p. 76). Al comienzo del último poema de los Cantos se lee: "He tratado de escribir el Paraíso". En Mrs. Dalloway de Virginia Woolf, Septimus está leyendo el Inferno: "Septimus, deja tu libro", dijo Rezi, cerrando con suavidad el Inferno". En una entrada de su diario, Virginia Woolf apunta: "Estoy leyendo a Dante, \& digo, sí, esto hace cualquier escritura innecesaria. Esto 'sobrepasa' la escritura...” (Woolf, The Diaries 20/8/ 1930).

La obra quiere descubrir: “...que de los hechos mi decir no difiera” (Inf. XXII, 12). Hay vocación de verdad, aunque sea dura, en su arte. Ya en el Paraíso escribirá:

\author{
"y al fin, de luz en luz, por este cielo \\ he oído cosas que si las repito, \\ amargarán a muchos paladares; \\ mas si me muestro como amigo tímido \\ de la verdad, no viviré entre aquellos \\ que a nuestro tiempo llamarán antiguo" \\ (Par., VII, 114-120). \\ Traducción de José María Micó (Micó 2018).
}

Para el Dante el mal es autodestuctivo. Por ejemplo, se encuentra con Felipe Argenti, y "el orgulloso espiritu del florentino .... se desgarraba a sí mismo con los dientes" (Inf. XVIII, 62-63). Y en otro momento dice: “¿Por qué las culpas nos desgarran de ese modo?" (Inf. VII, 21). Beatriz le dirá que no hay que ser como "el cordero, que deja la leche de su madre y, sencillo y alegre, lucha él mismo contra su propio bien" (Par. V, 82-84). Como el buen aristotélico que era, piensa que "la virtud debe ser alegre". Dice que "la obra virtuosa debe por sí misma granjearse a los amigos, dado que en nuestra vida necesitamos de ellos..." Luego reitera: "el fin de la virtud es que nuestra vida sea alegre" (El Convite, I, xviii, 7 y 12). 
Vientos contrarios que no cesan los lanzan, los hacen girar en sus torbellinos y son lanzados otra vez. Los que han pecado de amor sensual, "sometiendo la razón al impulso", son arrastrados por el viento, como bandadas de pájaros que vuelan descontrolados en la borrasca (Inf. V, 39). El vendaval de pasiones los empuja y revuelve sin darles esperanza de reposo y paz. Hemos salido recién del Limbo y entrado al segundo círculo del Infierno. Vemos a Semíramis, a Elena y a Paris, a Dido, a Cleopatra, a Tristán... Virgilio le señala más de mil muertos por amor. Dante siente que desfallece de compasión. Pero no intenta hablar con los famosos sino con dos sombras que "van juntos y parecen flotar más ligeros en el viento" (Inf. V, 75). Una breve calma permite al Dante conversar con ellos. Es ella la que cuenta. Él, que está a su lado, nada dice y nada dirá. Francesca se casó con Gianciotto, hermano de Paolo. Pero "el amor, que no perdona al amado que no ama", unió a Francesca y Paolo con una atracción tan fuerte, que "como ves, no me abandona todavía" (Inf. V, 103-105). Giancciotto los sorprendió y los mató a los dos, por lo cual está en la fosa de los Caínes.

"Entonces me volví de nuevo a ellos

y dije: "Francesca, tu martirio

me arranca lágrimas de tristeza y compasión.

Pero dime: en el tiempo de los dulces suspiros, ¿por qué y cómo les permitió el amor conocer los dudosos deseos?"

Y ella a mí: "No hay mayor dolor que recordar el tiempo feliz en la miseria.

Tu maestro lo sabe bien.

Pero si quieres conocer con tanto afecto

la primera raíz de nuestro amor

lo haré como quien llora y dice.

Leíamos, un día, por gusto

cómo hirió el amor a Lanzarote;

estábamos solos y sin sospechas.

Leyendo muchas veces los ojos se encontraron,

y perdieron los rostros sus colores;

pero sólo un momento fue el que nos venció.

Cuando leímos que la anhelada sonrisa

fue besada por tal amante,

éste, que ya no se apartará de mí,

la boca me besó temblando entero.

Galeoto fue el libro y lo escribió él:

desde ese día no seguimos leyendo.

Mientras un espíritu me decía esto,

el otro lloraba, y de compasión

sentí que desmayaba y moría. 


\section{Y caí como un cuerpo muerto cae" \\ (Inf., V, 115-142). ${ }^{2}$}

El Dante ha querido conocer más detalles, cómo surgió el primer beso. Cuando leen que Lanzerote besa "la anhelada sonrisa", Paolo y Francesca se besaron. Para el Dante en esa "anhelada sonrisa" ("il disiato riso") aparece el alma. "¿Qué es la sonrisa”, escribe en El Convite, "sino un relámpago del gozo del alma, esto es, una luz que aparece por fuera igual que está adentro?" (El Convite, III, XVIII, 11). El yo más yo de quien sonríe, por un instante, se hace carne en su sonrisa. En ese relámpago, el gozo está tan afuera como adentro. Querer besar esa sonrisa es querer ese yo íntimo y secreto que se asoma en el cuerpo como si fuera su misterio impalpable. El amor erótico se dirige a un individuo. Mejor dicho: a esa persona tal como aflora en su cuerpo. Roger Scruton ha desarrollado este tema, por ejemplo, en su libro Sexual Desire (Scruton 1986).

El Dante, conmovido por lo que le cuenta Francesca, cae "como un cuerpo muerto cae". El pentámetro comienza por un yambo al que suceden cuatro troqueos que viajan bien al castellano: "y caí/como un/ cuerpo/ muerto/ ca e/. En el original, son cinco troqueos donde resuenan los sonidos que se repiten: "e caddi come corpo morto caddi”. La música de este verso no se olvida.

Dante y Virgilio llegan a un pantano. Están ahí las “almas que estuvimos tristes en el aire dulce alegrado por el sol” (Inf. XVII, 121-122). Vemos de ellos solo los gorgoritos de sus suspiros en el fango. No pueden pronunciar palabras enteras, su lamentación se les atraviesa en la garganta con el barro. Son los ácidos, los que han pecado de acidia que, según Tomás de Aquino - a quien el Dante ha leído bien y sigue muy de cerca- llega "a cortar la voz" (Suma Teol. I-II. q. 35 a.8). La acidia o acedia es "una tristeza", escribe Tomás de Aquino, "que de tal manera deprime el ánimo del hombre, que nada de lo que hace le agrada" (Suma Teol. II-IIae. q.35 a.1). Es un ácido corrosivo de la vida. A los monjes les solía caer encima esta desazón en mitad de la vida y a medio día, cuando ya parecían haber encontrado definitivamente su camino. La negación de la luz ocurre a pleno sol. Es el "demon de midi". Por eso la acidia implica "cierto hastío para obrar" que "versa sobre lo que es malo en apariencia y bueno en realidad" (Suma Teol. II-IIae. q.35 a.1). No es la tristeza en sí lo malo, sino la tristeza del bien, la que tiende a suscitar una huida del bien. De la acidia nace, por ejemplo, la desesperanza, la animadversión a quienes hacen el bien, y eso da lugar al rencor y a la amargura que le acompaña (Suma Teol. II-IIae.q,35 a.4 obj.3 y 4). Los ácidos se quedan sumidos en su pantano, siguen hundidos en su rencorosa negación del sol.

2 La traducción es mía como los son todas las citas de la poesía del Dante, salvo cuando se indica al traductor. 
Ven un lago "que por estar helado tenía más aspecto de vidrio que de agua" (Inf. XXXII, 23-24). A medida que penetramos con Virgilio y Dante en ese inmenso embudo que es el Infierno, aumenta la participación de la inteligencia, del raciocinio y el cálculo en los pecados, y con ellos, su gravedad. Lo muestra el paisaje que se va volviendo de hielo. Por eso, en lo más profundo, están falsarios como el maestro Adamo, que devaluó la moneda florentina falsificándola. Acuñó florines oro de veintiún carates en lugar de los veinticuatro legales. Me entero de esto leyendo el completísimo comentario de $L a$ Divina Comedia que escribió Charles Singleton (Singleton 1970 y 1973). Y, de paso, recomiendo, asimismo, Para leer "La Divina Comedia” de Joaquín Barceló (Barceló $2003)^{3}$.

Todavía mas abajo, están los traidores. "Dime quién eres”, pregunta Dante a una sombra aprisionada en hielo. "Soy fray Alberigo, soy quien da fruto de mal huerto"... Alberigo tuvo una disputa con un pariente suyo. Habiéndose ya producido la reconciliación, en plan de amistad, los convidó a comer a él y a su hijo. Al decir fray Alberigo "venga la fruta", entraron los asesinos que dieron muerte al padre y a su hijo. Dante le dice sorprendido: “¿Ya estás muerto?” Pues lo tenía por vivo en la tierra. A lo que contesta el fraile: apenas el alma traiciona, como yo lo hice, "el cuerpo es poseído por un demonio, que desde entonces lo gobierna hasta que se cumple todo el tiempo de su vida" (Inf. XXXIII, 126-132). Así, fray Alberigo, como Branco d'Oria -que asesinó a traición a su suegro- están en el Infierno y en la tierra. Los traidores mueren antes de morir y siguen vivos.

"El mismo llanto aquí llorar no deja,

Y el dolor que encuentra obstáculo en los ojos,

Se vuelve adentro y la ansiedad aumenta:

Pues las lágrimas primero se reúnen,

Y tal como viseras de cristal,

Llenan bajo las cejas todo el hueco"

(Inf. XXXIII, 94-99).

Traducción de Jorge Aulicino (Aulicino 2018).

En el último círculo, sumido medio cuerpo en el hielo, "el emperador del doloroso reino", de quien "procede todo el mal" sigue repitiendo lo que siempre hizo. Si Paolo y Francesca se siguen amando en el Infierno, "el padre de la mentira" sigue traicionando

3 Una nota personal: siendo yo estudiante de Filosofía leí, en unos números viejos de la Revista de Filosofía, un par de artículos de Joaquín Barceló sobre el Dante. Fue por ellos que leí La Divina Comedia. Después fui alumno de Barceló. 
(Inf. XXIII, 144). ¿A quiénes? A los más grandes traidores, es decir, a sus discípulos más cercanos: Bruto, Casio, Judas. Y mientras lo hace, llora. Al verlo, dice Dante: "No morí y no permanecí vivo" (Inf. XXXIV, 25).

En las puertas del Infierno se lee: “dejen toda esperanza los que entran” (Inf. III, 9). El Infierno es la imposibilidad de la esperanza. Ese es su sentido existencial. Salir de él, es "ver de nuevo las estrellas" (Inf. XXXIV, 139).

En el Purgatorio se sufren pecados y crímenes equivalentes a los del Infierno. La diferencia es que los del Purgatorio se arrepintieron, pidieron perdón y ahora compensan su falta. Los del Infierno, no. Es el lugar "donde la culpa con el remordimiento se borra" (Inf. XIV, 137). La renovación de la vida es posible, el ser humano existe proyectándose, adelantándose a sí mismo. En el Infierno eso no ocurre. Los habitantes del Infierno han huido de lo humano y el resultado es la negación de su humanidad, es decir, de la posibilidad de influir en su futuro. Solo existe su pasado y el pasado no se puede cambiar.

"Yo soy de Montelfedro, yo soy Bonconte" ... "y voy con la cabeza baja" (Purg. V, 88 y 89). El líder de los Ghibelinos está en el Purgatorio. Fue con su apoyo que los guibelinos expulsaron a los güelfos de Arezzo y comenzaron las hostilidades entre Florencia y Arezzo. Luchó contra los güelfos de Florencia y fue derrotado en la sangrienta batalla de Campaldino el sábado 11 de junio de 1289. Por eso, su "cabeza baja". Los guibelinos como guerreros eran más duchos y experimentados, pero los güelfos eran más. Debido a ello, Bonconte no quería presentar batalla, pero el comandante de la infantería, el obispo Ubertini, lo empujó a hacerlo, según sostienen los historiadores Devries y Capponi (Devries y Capponi 2018, p. 85). El propio Dante, de veinticuatro años, combatió en esa batalla en la vanguardia de la caballería florentina que comandaba Vieri de' Cerchi e integraban ciento cincuenta escogidos de un total de algo de mil doscientos caballeros güelfos que lucharían ese día. Lo recuerda en una carta perdida a la que alude Leonardo Bruni, quien asegura que en ella describió esta "battaglia memorabile e grandissima ... dove portò gravissimo pericolo" e hizo incluso un plano de ella. Dante, según la carta que cita Bruni, "al principio sintió gran miedo", pero después "la mayor alegría" a causa del cambio de fortuna en el combate (Bruni, De la vita studi e costume di Dante, p. 4 y 5). Formar parte de la caballería era un gran honor y exigía cubrir los gastos de caballos, armas y servicio.

Bonconte, al mando de solo doce "paladines" muy aguerridos y experimentados, embistió a todo galope a la vanguardia florentina causando estragos con sus lanzas, mientras penetraban en profundidad en las filas. La idea era que la caballería de los güelfos, al ver venir a tan pocos, se precipitaría sobre ellos, momento en el cual cargaría la caballería guibelina. Había más de dos caballeros güelfos por cada guibelino. La infantería de los güelfos también era superior en número. El arriesgado plan guibelino buscaba contrarrestar esa diferencia. 
Una crónica de la época afirma que "lucharon con más valor que los paladines de Francia"4 . La caballería de los güelfos florentinos -los que no habían sido desmontados por las feroces lanzas de los doce- cedió y retrocedió mucho, pero sin dispersarse. $\mathrm{Su}$ plan era defensivo. Por eso, cuando el grueso de la caballería guibelina se lanzó al ataque, no tuvo el efecto esperado. Y la infanfería de los guelfos comenzó a hostigarlos por los flancos. Antes que la infantería guibelina entrara en combate -rezago que resultó fatal- un batallón de caballería florentina al mando de Donati, que estaba oculta y en reserva, cargó sobre un flanco de la caballería enemiga, lo que tomó de sorpresa y desordenó a los guibelinos. La caballería de reserva de los guibelinos, al mando de Guidi Novello Guidi, decidió retirarse del campo de batalla sin combatir. El ejército güelfo, en dos brazos, empezó a rodear a los guibelinos como una herradura. Las flechas de la infantería llovían, cuenta un cronista, y los soldados guibelinos se metían bajo los caballos enemigos y con sus dagas vaciaban sus intestinos que caían al campo ${ }^{5}$. Hacía un calor húmedo y la lucha cuerpo a cuerpo pronto llenó el campo con nubes de polvo, gritos y gemidos, carnes abiertas por los tajos, sangre que corre y se aposa, miembros mutilados.

Uno de los dos comandante de los güelfos, Guillaume de Durfort, es muerto en la lucha. El obispo Ubertini también cae combatiendo. La lista es larga. Más de mil setecientos guibelinos quedaron tendidos en el campo. Así comenzó el predominio de Florencia en la Toscana. Dos destacados capitanes florentinos -Donati y Vieri de' Cerchi- serán posteriormente los líderes de los partidos negro y blanco en los que se dividirán los güelfos de Florencia. Bonconte, sangrando y herido de muerte, huyó hasta el río que se llenó de cuerpos destrozados. Es posible que el Dante y otros hayan perseguido su rastro por hacerlo prisionero. Nunca se encontró su cuerpo. Poco tiempo después, el Dante combatiría en el sitio del castillo de Caprona, cerca de Pisa, lo que también menciona en sus versos. Es de suponer que son imágenes de esas batallas las que reaparecen en muchas de las escenas cruentas de La Divina Comedia.

En el instante en que moría, cuenta el poema, Bonconte de Montefeldro se arrepintió de sus pecados. "El ángel de Dios," me acogió, cuenta Bonconte. "Y el del Infierno gritaba: “¿Por qué me privas de él? Te llevas lo eterno de él por una lagrimita que me lo arrebata" (Purg. V 104-107). El arrepentimiento - esa "lagrimita"- incluso a la hora nona, redime y permite ver las estrellas.

La Divina Comedia está llena de personajes políticos involucrados en los conflictos en los que Dante, de una u otra manera, participó. Hasta los treinta años, fue un poeta, un estudioso de la filosofía y la literatura, un intelectual y un padre de familia. Sin fortuna ni nobleza se movía en los círculos más exclusivos de la sociedad florentina y fue amigo íntimo de aristócratas de gran riqueza y poder, como el poeta Guido Calcacanti, entre otros. Después de esa edad "fue poseído por el demonio de la

Pseudo-Brunetto, citado en Devries y Capponi 2018, p. 113.

Compagni, citado por Devries y Capponi 2018, p. 120. 
política" (Santagata 2016, p. 55) Incluso en el Paraíso aparecen los temas políticos. Dante muestra que "la misión del poeta" es "convertir en poesía lo no poético" (Elliot, p. 167).

Fustiga a su Florencia, "la ciudad partida," tan "llena de envidia que ya se sale del saco..." "Soberbia, envidia y avaricia son las tres chispas que han inflamado sus corazones" (Inf. VI, 49-50. 61 y 74-75). Dante escribe en el exilio. Lamenta, en una carta a los condes de Romena, no poder asistir a un entierro de su padre pues la pobreza lo ha "despojado de caballos y de armas" (Carta a los condes de Rómena, p. 796). Tuvo importancia política en el partido de los blancos y llegó a ser nombrado prior, es decir, miembro del comité que gobernaba Florencia. El partido de los negros era próximo al Papa Bonifacio VIII. Los blancos defendían la autonomía política. Pero estas diferencias se mezclaban, atenuaban y confundían con intereses y ambiciones personales. Dante integró una embajada de Florencia ante el Papa Bonifacio VIII. Estando en Roma, los negros se hicieron del poder y comenzaron los juicios en contra de los dirigentes de los blancos. Muchos de ellos partieron al exilio, incluido, por cierto, el líder del partido, Vieri dei Cerchi, que era un importante banquero, lo que ocasionó fuga de capitales y quiebras (Santagata 2016, p. 140 y ss.). Los blancos forman entonces una alianza con los gibelinos -los antiguos enemigos de Campaldino- y contra los negros. Se supone que Dante participó en la reunión que selló el pacto y es seguro que fue miembro del Consejo de los Doce que digiría la coalición. Posteriormente, es condenado a la hoguera. De allí su exilio. La pasión política - pese a períodos de estudio y escriturano lo abandonará más.

También critica a Roma. Piensa que el poder temporal de los papas es una corrupción de la enseñanzas de Cristo. En la Edad Media se creía que el emperador Constantino al irse a Bizancio había dejado al papa Silvestre I, que le curó la lepra, como su sucesor en el Imperio Occidental. De tal modo que, según "la donación de Constantino", el sucesor de Pedro era, a la vez, el legítimo sucesor de César. Existía un documento en el que constaba el "donado" de Italia al papa Silvestre I. A partir de él, se sostenía que todo el poder que había sido de Roma imperial correspondía al Papado. El documento era una falsificación elaborada en el siglo VIII, pero eso se vino a descubrir recién en el XV.

En su tratado De la monarquía, Dante sostiene que "los regímenes políticos rectos procuran la libertad, es decir, que los hombres vivan para sí mismos" (De la monarquía I, xii, 10). Pese a no poner en duda la autenticidad del documento de Constantino, lo considera nulo desde un punto de vista conceptual. Defiende la separación del poder religioso y el poder temporal, anticipándose a la doctrina liberal de la separación de la Iglesia y el Estado, es decir, en su caso, del Papado y del Imperio temporal. El ser humano, dice sosteniendo una teoría original suya -apartándose en esto de Tomás de Aquino- tiene un doble fin, uno temporal y otro espiritual. "El fundamento de la Iglesia es Cristo...el fundamento del Imperio, en cambio, es el derecho humano...Le fue necesaria al hombre una doble dirección en orden a este doble fin, a saber, la del sumo pontífice, que, según la verdad revelada, lleve al género humano a la vida eterna, y la del emperador, que, según las enseñanzas filosóficas, conduzca al género humano hacia la felicidad temporal" (De la monarquía III, x, 7 y xvi, 11). Con esta tesis del doble fin Dante, en su filosofia política, "da muestras de una verdadera originalidad" 
(Barceló 1990). Dante pensaba que un imperio secular y universal era necesario para lograr la paz universal. Las pequeñas repúblicas y principados que fragmentan Italia viven en enconados e irremediables conflictos violentos entre ellos y adentro de ellos mismos. Ha llegado a la conclusión de que una extensión mayor es la llave de la paz. Ve en las aspiraciones de rey Enrique VII -con quien se entrevistó- la esperanza de la unidad de Italia.

Marco Lombardo, político veneciano, con quien se encuentra Dante en el Purgatorio, le dice que Roma tenía antes dos soles: "uno y otro camino hacían ver, el del mundo y el de Dios". Pero se han unido "la espada y el báculo". Hoy "la Iglesia de Roma, por confundir en sí dos gobiernos, ha caído en el fango" (Purg. XVI, 106- 110 y 128-129). Dante halla al papa Bonifacio VIII en el Infierno, condenado por simonía que consiste "en recibir dinero por la gracia espiritual de los sacramentos", según Tomás de Aquino (Suma Teol. II-IIae q.100 a.). Embolsó y está embolsado en el Infierno. El Dante lo increpa, como no lo hace con casi ningún condenado, aludiendo a la ramera del Apocalipsis prostituída por los reyes, en este caso, por los papas de su tiempo. Esto ocurre en el canto XXVII del Infierno. Y el canto XXVII del Paraíso -la coincidencia numérica no es casual- San Pedro le dirá que "quien usurpa en la tierra el lugar mío" y repite "el lugar mío, el lugar mío" ha hecho de "mi cementerio cloaca de sangre" (Par. XXVII,22-24). El aludido es Bonifacio VIII, a quien Dante considera el enemigo número uno por haber apoyado el partido de los negros, causa, en definitiva, de la derrota política de los blancos y su exilio. Y más adelante dice San Pedro: "No fue intención nuestra... que las llaves que me fueron concedidas se convirtieran en pendón de guerra que contra los bautizados combatiese" (Par. XXVII, 46-51).

\section{V}

Contra el muro, como ciegos mendigando a la salida de la iglesia, se confunden con la palidez de las piedras. Se apretujan y apoyan unos a otros y contra la muralla. Asoman sus caras por detrás de los otros por suscitar compasión pidiendo limosna. Los envidiosos tienen los párpados cocidos como se hace con los gavilanes salvajes para domesticarlos. Así es como se preparan para la libertad del Paraíso. El Dante sufre al mirarlos en ese estado.

Pero, ¿por qué han sido cegados los envidiosos?

"Sabe que yo fui Guido del Duca.

Fue mi sangre tan inflamada por la envidia

Que si hubiera visto a un hombre contento

me habrías visto ponerme lívido"

(Purg. XIV, 81-84).

La envidia, escribe Tomás de Aquino, es "tristeza del bien ajeno" (Suma Teol. II-IIae, q.36 a.1). Aristóteles había dicho que es una "tristeza con turbación que se siente por el éxito, pero no del que no lo merece, sino del que es nuestro igual o semejante" (Ret., $1387 \mathrm{~b} 20$ y sigs). No es que ese bien ajeno sea inmerecido, entonces, ni que nos amenace, 
ni que nos duela el que a nosotros eso nos falte. Como plantea Aristóteles en estos casos no se trata, propiamente, de envidia sino de indignación o némesis, temor y emulación o celo, respectivamente (Ret. II, xviii, 1386b 10 y ss.). El dolor propio de la envidia nace, simplemente, del hecho de la buena fortuna del otro y es mayor si ese bien es merecido. El envidioso, escribe Tomás de Aquino siguiendo a Aristóteles, "se entristece del bien de quienes son dignos de él" (Suma Teol. II-IIae, q.36. a.3 ob.3). Es tristeza ante lo que debiera alegrarnos. Y ¿por que? Ese "bien de otro se considera como mal personal porque aminora la propia gloria o excelencia” (Suma Teol. II-IIae, q.36 a.1).

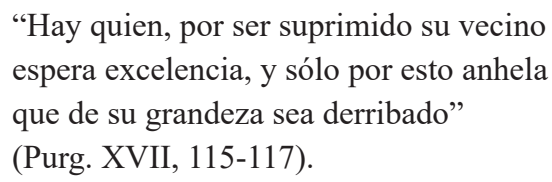

La tristeza del envidioso arranca de que mira su propio bien en función del de los demás, es decir, como estrictamente relacional. Su bien es por completo dependiente de los bienes de los otros. Es decir, el drama del envidioso es que su bien está esencialmente supeditado al que poseen otros y, por tanto, carece de autonomía. Esa mirada volcada hacia afuera y ciega respecto de sí mismo, es lo que su dolorosa ceguera actual invierte.

De la envidia puede derivarse el odio."Más contenta fui con el daño ajeno que con la ventura propia”, dice Sapia, una sienesa que Dante encuentra en el Purgatorio (Purg. XIII, 110-11). De "la envidia, se sigue la satisfacción de ver el mal que le ha ocurrido" al envidiado (Suma Teol. II-IIae q.36 a.4 ob.3). Porque "siendo la envidia tristeza provocada por el bien del prójimo, conlleva como resultado hacernos odioso su bien, y ésa es la causa de que la envidia dé lugar al odio" (Suma Teol. II-IIae q.34 a.6).

Guido Del Duca sugiere una explicación para la envidia: proviene de poner el corazón donde "compartir está prohibido" (Purg. XIV, 87). Dante queda intrigado y al rato le pregunta a Virgilio qué quiso decir Guido. Virgilio contesta:

"pues vuestros deseos apuntan

a lo que al compartirlo, disminuye,

la envidia hace que el pecho suspire"

(Purg. XX, 49-51).

Los economistas y sociólogos hoy llaman "bienes posicionales" aquellos cuyo valor depende de su exclusividad. Por ejemplo, el valor las acciones de un club social o de las propiedades de un barrio pueden disminuir si se masifican. En términos del Dante, su valor "al compartirlo, disminuye". Es muy posible que Dante haya estado pensando en la fama. Si todos ganan el premio, nadie gana el premio; si todos son famosos, nadie es famoso. La envidia hiere al envidioso porque siente que el bien de otro disminuye "la gloria o excelencia" propia, como plantea Tomás. El consejo de Guido, explica Virgilio, es poner el corazón en bienes que no se agotan al compartirse por muchos, sino que, por el contrario, al difundirse se multiplican. La imagen es la de una luz que cae sobre el agua o un espejo y no se pierde sino que rebota. Virgilio luego habla del 
"bien infinito e inefable" y del amor de caridad que aumenta y crece mientras más se ama, de modo que el amor de uno acrecienta el del otro, "como espejos que se reflejan uno en otro" (Purg. XV, 75). El Dante está contrastando la envidia con su opuesto: "La envidia" escribe Tomás, se opone a la caridad, pues esta "goza con el bien del prójimo" (Suma Teol. II-IIae, q.36 a.3).

Dante sufre al mirar a los envidiosos enceguecidos y que, apoyándose unos en otros, parecen estar mendigando. Ese actitud mendicante sugiere el carácter menesteroso del que envidia, su dependencia vital del bien de otro. Y su apoyarse unos con otros es el reverso de lo que hacen los envidiosos. La compasión que siente Dante ante ellos es el opuesto de la envidia. "El envidioso", escribe Tomás, "se entristece en realidad del bien del prójimo; el misericordioso, en cambio, de su mal" (Suma Teol. II-IIae, q.36. a.3 ob.3). Dice que a la misericordia compete "volcarse en los otros" y por eso "entre todas las virtudes que hacen referencia al prójimo, la más excelente es la misericordia" (Suma Teol. II-IIae, q. 30 a.4).

En el Purgatorio, el Dante quiere resaltar la libertad humana. No somos víctimas de lo inevitable, ni de los cielos ni de nuestros apetitos. El mal moral no nos apresa si no nos dejamos apresar por él. "Tenéis innata la virtud que aconseja y tiene la puerta del consentimiento" (Purg. 18, 62-63 y 65). Esta "innata libertad" permite acoger o rechazar "los buenos o los malos amores" (Purg. 18, 62-63 y 65, 68). El arrepentimiento -esa "lagrimita"de Bonconte- expresa la libertad que, si bien no cambia el pasado y obliga a la purgación, nos libera de su cárcel. Por el arrepentimiento renace la esperanza. Dante sale del Purgatorio "dispuesto a subir a las estrellas". Los tres libros el Inferno, el Purgatorio y el Paradiso terminan con la misma palabra: estrellas ("stella").

Al término de los poemas a Beatriz, que configuran el libro La Vita Nuova, Dante espera llegar a "decir de ella lo que nunca se ha dicho de ninguna" (La Vida Nueva, XLII). Sus escritos posteriores, sin embargo, siguen otros derroteros. El proyecto queda en suspenso. El poema de amor que cumpla esta promesa será, al fin, La Divina Comedia ${ }^{6}$.

6 Esto no significa que en el momento de esa promesa Dante haya tenido in mente La Divina Comedia como tal o haya ya estado escribiéndola. En la Vita Nuova, Dante dice que ha decidido no hablar de Beatriz hasta que pueda "tratar más dignamente de ella". Y añade: "Y me esfuerzo por conseguirlo" (La Vida Nueva, XLII). Esto puede entenderse como que ya trabaja en esa obra. De lo que deduce Santagata que el poema prometido "ciertamente no es La Commedia" (Santagata 2016, p. 87). Es posible que entonces haya estado efectivamente escribiendo otro poema - un poema en latín sobre Beatriz, como propone Santagata (Santagata 2016, p. 88)-. Pero también puede haberse estado preparando para su ambiciosa tarea a través del estudio. Después de La Vita Nuova, como he sugerido, la obra de Dante se mueve en otras direcciones, de modo que ese proyecto queda pendiente. Lo que importa, a mi juicio, es que La Divina Comedia fue el poema que vino a cumplir, en definitiva, esa promesa. 
Cuando, por fin, se reencuentran -viene ella vestida "del color de llama viva"- en los últimos cantos del libro El Purgatorio, "no hay gota de su sangre que no tiemble". Ella es la única que en todo el poema dice su nombre, Dante. Él reconoce "la antigua llama". No es verdad que Beatriz -que es sabia- sea un mero símbolo de la sabiduría. Al volverla a ver, Dante la ama en cuerpo y alma. Vuelve a sentir "l'antica fiamma" (Purg.XXX, 33, 46-48).

El viaje por el Infierno y el Purgatorio ha sido un castigo impuesto por ella, pues "él se olvidó de mí y se dio a otros amores" (Purg.XXX, 126). Ha sido un peregrinaje, un viaje de formación y descubrimiento "para darle experiencia plena" (Inf. XXVIII, 48). Pues ha sido Beatriz quien le ha pedido a Virgilio que guíe a Dante en su recorrido por "la ciudad del dolor". Dante se baña en dos ríos, el Leteo -el olvido- y el Eunoe -que alude a la memoria-. Entrar al Paraíso supone una mezcla de olvido y memoria. "Remember to forget", escribió Philip Roth.

Virgilio ha dicho del Dante que "va buscando la libertad, que es tan amada, como sabe quien por ella renuncia a la vida" (Purg. I, 71-72). Y ya después del Purgatorio y en Jardín del Edén que antecede al Paraíso, le dice al poeta: "No esperes ya mis palabras ni mi consejo; libre, recto y sano es tu albedrío" (Purg. XXVII, 140). Es la culminación de un proceso de aprendizaje y transformación personal. Este "viaje de ascensos" resulta en "la libertad, la libertad para ser según las más altas exigencias internas de su propia naturaleza humana” (Took 2020, p. 146 y p. 150). Lo último que Dante dirá Beatriz es: "Tú, desde la esclavitud, me has traído a la libertad".

La mujer amada aquí no es la "femme fatale", no es causa de perdición, sino que, por el contrario, de sanación. A su modo, continúa esta tradición Rousseau, Austen en Pride and Prejudice, también el Don Juan de Zorrilla, y con variantes y transformaciones de alguna manera, está presente hasta hoy. En la literatura popular es lo que mueve la historia de Shades of Grey, por ejemplo ${ }^{7}$. Quizá el primer poeta que lo vio así fue Guinizelli, a quien Dante llama "padre mío" y "de los nuestros, el mejor" (Purg. XXVI, 97-98). Así dicen lo últimos veros del soneto "I' vo' del ver la mia donna laudare".

$$
\begin{aligned}
& \text { " rebaja el orgullo de quien la saluda, } \\
& \text { hace ella de nuestra fe al que no cree } \\
& \text { y no puede acercársele hombre vil } \\
& \text { y, más aún, digo, tiene mayor virtud: } \\
& \text { ningún hombre puede pensar mal tras verla". }
\end{aligned}
$$

Dante y Beatriz, mientras suben por el Paraíso y hacia las estrellas, van conversando: "Pero ella que mi deseo conocía, empezó a hablarme sonriendo tan feliz, que en su cara Dios parecía gozar" (Par. XXVII 103-105). 
Guiado el último tramo por San Bernardo, teólogo de la mística cristiana, Dante busca el fundamento lo que existe, lo que borra la nada y sostiene a cada ente en su ser, es decir, la causa de todas las causas, y el sentido último de la vida y su incesante movimiento. Pero al aproximarse al fin de "todos los deseos" descubre que supera su entendimiento: "No eran para aquello mis alas" (Par. XXXIII, 46 y 139). Entonces, en un fulgor, comprenderá que su voluntad está girando como rueda movida por "el amor que mueve al sol y a las otras estrellas" (Par. XXXIII 143-145), un amor cuya presencia ya sentía amando a Beatriz.

El frío Primer Motor de Aristóteles y Tomás de Aquino es visto por Dante “como amor... el poder del amor impide el caos" y sostiene el universo (Mazzotta 2014). Dante se asoma así adonde "el gozo es por siempre" (Par. X, 148), lo que está por comenzar cuando el poema termina. Eso es lo que recuerda y ha podido escribir. La memoria y el lenguaje fallan. Habla de "un sueño" que al despertar se borra, salvo "la pasión que permanece impresa" (Par. XXXIII, 58-60).

Vuelvo atrás: su celosa redentora le ha dicho que solo por un tiempo se sostuvo su amor y su virtud con "mi presencia" y "mis ojos juveniles." Le reprocha que hubo “cierta jovencita”, un amorío, otra "vanidad breve”. Le dice al Dante: “No sabías que aquí el hombre es feliz?” (Purg. XXX, 121-122, 59-60 y 75). Es decir: en el Paraíso, y en ningún otro lugar. (A fin de cuentas, ¿no es esta la enseñanza que deja Lacan?).

En tiempos en los que la publicidad comercial, la política y los proyectos de edificación pseudosicológico -se parecen tanto- repiten y repiten con cansadora banalidad que hemos nacido para "cumplir nuestros sueños" y ya basta, conviene recorrer este poema: en esta tierra esos sueños, como dirá Beatriz, "no cumplen enteramente promesa alguna”. Y no podrán hacerlo nunca. ¿Somos capaces de soportar la verdad sin hundirnos en el infierno de la desesperanza?

\section{Referencias bibliográficas}

Aquino, Tomás de, Suma Teológica, I-II, q. 35; II-IIae, q. 30, 34 y 36; II-IIae, q.100. BAC, Bilioteca de Autores Cristianos. Edición dirigida por los Regentes de Estudio de las Provincias Dominicanas de España. Cuarta reimpresión. 2001. www.dominicos.org

Aristóteles (1990), Retórica. Traducción de Carlos García Agual. Madrid: Biblioteca Clásica Gredos. Sexta edición, 2014.

Auerbach, Erich (1929), Dante. Poet of the secular world. Translated by Ralph Manheim. New York: A New York Review of Books published by The New York Rview of Books. 2001, p. 142.

Barceló, Joaquín (2003), Para leer La Divina Comedia. Santiago: Editorial Biblioteca Americana.

(1990), Selección de escritos políticos de Dante. Santiago: Estudios Públicos No 40. https://www.cepchile.cl 40 Barceló Pdf. p. 1 
Bruni, Leonardo (1901), The Life of Dante en The earliest lives of Dante. Translated by James Robinson Smith. New York: Yale Studies in English, Henry Colt and Company. Exported from Wikisource 06/18/17.

Dante Alighieri (1985), La Nueva Vida. Traducción y notas de Julio Martínez Mesanza. Madrid: Ediciones Siruela.

(1965), El Convite, en Dante, Obras Completas. Traducción de Nicolás González Ruiz sobre la interpretación literal de Giovanni M. Bertini. Madrid: BAC, Biblioteca de Autores Cristianos.

(1965), De la Monarquía, en Dante, Obras Completas. Traducción de Nicolás González Ruiz sobre la interpretación literal de Giovanni M. Bertini. Madrid: BAC, Biblioteca de Autores Cristianos.

(1965), "Carta a los condes de Rómena", en Dante, Obras Completas. Traducción de Nicolás González Ruiz sobre la interpretación literal de Giovanni M. Bertini. Madrid: BAC, Biblioteca de Autores Cristianos.

(1965), "Carta al Can Grande”, en Dante. Obras Completas. Traducción de Nicolás González Ruiz sobre la interpretación literal de Giovanni M. Bertini. Madrid: BAC, Biblioteca de Autores Cristianos.

(1965), La Divina Comedia, en Dante. Obras Completas. Edición bilingüe. Traducción de Nicolás González Ruiz sobre la interpretación literal de Giovanni M. Bertini. Madrid: BAC, Biblioteca de Autores Cristianos.

(2018), La Comedia. Prólogo, Comentarios y Traducción de José María Micó. Barcelona: Acantilado.

(2018), La Divina Comedia. En versión de Jorge Aulicino. Santiago: Ediciones Lom.

Dante Alighieri y José María Mico (2018), Comedia. Barcelona: Acantilado.

Devries, Kelly and Niccòlo Capponi (2018), Campaldino 1289. The battle that made Dante. Oxford: Osprey, Bloomsbury Publishing Plc.

Dyhouse, Carol (2017), Hearthrobs. A history of women and desire. Oxford: Oxford University Press.

Elliot, T. S. (1965), "Lo que Dante significa para mí", en T. S. Elliot, Criticar al crítico. Traducido por Manuel Rivas Corral. Madrid: Alianza Editorial. 1967.

Freccero, John (1993), "Allegory and Autobiography", en Raphael Jacoff, The Cambridge Companion to Dante. Cambridge: Cambridge University Press.

Guinizzelli, Guido, “I'o vo' del ver la mia donna laudare”. https://www.atuttarte.it/

Hegel, G.W, (1842), Lecciones de Estética. Traducción de Alfredo Brotons Muñoz. Madrid: Akal, 1989. Segunda reimpresión 2011.

Kriesel C. James (2019), “Allegories of the corpus”, en Barański Sigmund G. y Simon Gilson, editors, The Cambridge Companion to Dante's Commedia. Cambridge: Cambridge University Press.

Mazzotta, Giuseppe (2014), Reading Dante. New Haven and London: Yale University Press. 
Pertile, Lino (2019), "Narrative Structure", en Zigmunt G. Barański and Simon Gilson, editors, The Cambridge Companion to Dante's Commedia. Cambridge: Cambridge University Press. 2020.

Singleton Charles S. (1954), Dante's Commedia. Elements of Structure. Baltimore and London: The Johns Hopkins University Press. Second printing, 1980.

(1970 y 1973), The Divine Comedy. Bilingual edition. Translated, with a Commentary. Princeton: Princeton University Press.

Santagata, Marco (2016), Dante. The Story of his Life. Translated by Richard Dixon. Cambridge, Massachusetts and London: Harvard University Press. Primera edición italiana, 2013.

Scruton, Roger (1986), Sexual Desire. A moral philosophy of the erotic. New York: The Free Press. A division of Macmillan, Inc. Ver, en especial, pp. 16-35 y 94-130.

Took, John (2020), Why Dante Matters. London, Oxford, New York, New Delhi, Sydney: Bloomsbury Continuum.

Woolf, Virginia (1930), The Diary (1977-1984) en Complete Works. Knowledge House. Kindle edition. 2020. 